\title{
Effect of Parameter Variation on the Viscosity of Ethanol Gel Propellants
}

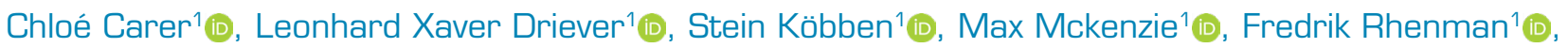 \\ Onno Van de Sype ${ }^{1}$ (D), Jesse van der Toorn ${ }^{1}$ [D, Casper van Wezel ${ }^{1} \mathbb{D}$, Constança Miranda de Andrade \\ Veiga $^{1}\left(\mathbb{D}\right.$, Aleksandrs Vinarskis $^{1} \mathbb{D}$, Botchu Vara Siva Jyoti ${ }^{1, *}$ (iD
}

1. Delft University of Technology - Faculty of Aerospace Engineering - Department of Space Engineering - Delft - The Netherlands.

*Corresponding author: b.v.s.jyoti@tudelft.nl

\begin{abstract}
This research investigated how the variation of temperature and shear rate affects the viscosity of ethanol gel propellants that use methyl cellulose as gellant and, in parts, use boron as energetic additive. Using a rotational viscometer in a cone-and-plate configuration, propellant viscosity data was recorded across a range of temperatures and applied shear rates. The temperaturedependence of the viscosity was modelled using an Arrhenius-type equation. For the high shear rates, the data was modelled using the Power Law, Herrschel-Bulkley model, Carreau model, and Cross model. For low shear rates the used model was the rearranged Herrschel-Bulkley model. The temperature investigation suggested that the trend of decreasing viscosity with increasing temperature, predicted by the Arrhenius-type equation, is only applicable until approximately $320 \mathrm{~K}$, after which the gel viscosity increased strongly. At high shear rates, the gel behaved in a shear thinning manner and was modelled most accurately by the Cross model. At low shear rates, the gel was shear thickening up to its elastic limit, which was found to lie at $0.41 \mathrm{~s}^{-1}$.
\end{abstract}

Keywords: Gel propellant; Rheology; Shear rate; Temperature; Methyl cellulose.

\section{INTRODUCTION}

A growing number of sovereign states are acquiring the capacity for space programs of their own with the number of satellites orbiting Earth potentially quintupling in the next decade (Ryan-Mosley et al. 2019). This rise in space operations is fuelled by technological innovation, which creates more cost-effective and, thus, lucrative space activities (Ryan-Mosley et al. 2020). Innovation and the development of new and improved technologies are critical, in order for current trends to progress into the future. In the case of rocketry, exploration of new propellant types may have the potential to lastingly shape the abilities of rockets.

Gels are defined as liquids which rheological properties have been altered using the addition of a gellant (Ciezki et al. 2017). The initial motivation to develop gel propellants arose from their superior energetic performance relative to liquid bipropellant systems (Natan and Rahimi 2001). Furthermore, gels have demonstrated to be inherently safer as they are more resistant to sloshing and leaking, two properties that are otherwise largely exclusive to solid propellants (Ciezki et al. 2017). At the same time, they offer the ability to build controllable engines, a property that is primarily unique to liquid propellants (Ciezki et al. 2017).

Received: Jul. 25, 2020 | Accepted: Nov. 13, 2020

Peer Review History: Double Blind Peer Review.

Section Editor: T. John Tharakan

This is an open access article distributed under the terms of the Creative Commons license. 
Thus, by using both the liquid and solid behaviour of gels, gel propellants have the potential to yield significant advantages over other types of propellants (Natan and Rahimi 2001).

Gels have been determined to be non-Newtonian fluids, a property that allows them to have a varying viscosity as a function of shear rate (Ciezki et al. 2010). Shear thinning or pseudoplastic fluids are fluids that exhibit lower viscosity at higher shear rates (Chhabra and Richardson 2008). This is particularly desirable for gel propellants as it allows them to reap the benefits that solid materials have as propellants in a quasi-solid state, whilst also being able to transition to a fluid state in order to be fed through pipes and injected into combustion chambers (Aggarwal et al.2015). To initiate this transition, a specific shear rate must be instigated, therefore knowing the exact relationship between shear rate and viscosity is crucial. Other rheological properties, such as how a gel behaves under varying temperature and how the chemical composition of a gel affects its rheology, are of equal interest.

Previously, researches have already been done on the rheological properties of gelled propellants (Jyoti et al. 2013b; 2013c; Jyoti and Baek 2014; 2015). This paper too aims to determine the rheological properties of potential ethanol-based gel propellants. These rheological properties determine the flow behaviour of the gels and understanding them is essential knowledge required for the design of gel propulsion systems (Ciezki et al. 2010). In addition, this paper focuses on the investigation of different models used to predict the propellant flow behaviour in a mathematical way. Such models are examined and fitted to data collected for different shear rates and for different temperatures. Knowledge about what models is applicable and how exactly they are can be used in later research for predicting the rheological behaviour of gel propellants. An important conclusion from previous research was: "the magnitude of apparent viscosity shifted to a much lower viscosity range with increase in operating temperature for all the gel propellant systems" (Jyoti et al. 2013c). In this paper however, data from a wider temperature range is taken into account and compared to the previous research where this conclusion was found (Jyoti et al. 2013b; Jyoti and Baek 2014). This was done because, the viscosity suddenly increases with increasing temperature, instead of decreasing with increasing temperature. Research into these properties and their sensitivity to environmental factors can provide valuable insight into what technology is required to deploy gel propellants, how gel propulsion systems should be designed and the restrictions that gel propellants impose.

Data was gathered by researchers at Delft University of Technology by using a rotational cone and plate viscometer to measure the viscosity of different gels under varying temperatures and shear rates. All gel propellants are ethanol based and are referred to using the codes Methyl cellulose 9 (MC9), Methyl cellulose 8 (MC8), Boron 20 (B20) and Boron 10 (B10). The prefix MC indicates that only the gelling agent, methyl cellulose, is used, B indicates the additional use of boron as an energetic additive and the number indicates the quantity of the respective component present as a percentage of the total weight. Shear stress, viscosity and temperature were measured at increasing low shear rates ranging from 0 to $12 \mathrm{~s}^{-1}$ to investigate elastic behaviour. Subsequently, the same measurements were taken for a high shear rate range of up to $1000 \mathrm{~s}^{-1}$ to yield results pertaining to shear thinning or thickening behaviour. Finally, the viscosity was measured at varying temperature for each of the gels.

\section{MATERIALS}

In order for the propellant to obtain gel-like behaviour, a gellant (also known as gelling agent) must be added. In the present work, ethanol (99.8\% pure; Sigma Aldrich Corporation, CAS number: 64-17-5) was selected as the base fuel and organic methyl cellulose (MW: 40,000; Sigma Aldrich Corporation; CAS number: 9004-67-5) was used as gellant. For the metallized ethanol gel system, boron ( $97 \%$ pure) nanoparticles (10 and $20 \mathrm{wt} \%$ ) were chosen, the particle diameter varying from 230 to $420 \mathrm{~nm}$, with $290 \mathrm{~nm}$ as the most probable average diameter. Both the gellant and the boron additive shall be discussed in this section.

\section{Methyl cellulose as a gellant}

Methyl cellulose, commonly known as MC, is an artificial biomaterial derived from naturally occurring cellulose (Nasatto et al. 2015), which can be used as a gellant for fuels such as ethanol (Jyoti et al. 2013a). Methyl cellulose has a general structure as depicted in Fig. 1 and is composed of oxygen, hydrogen and carbon only. Thus, its elements are of low molecular weight, making MC suitable as a gelling agent in terms of efficiency for applications in rocket fuel. 


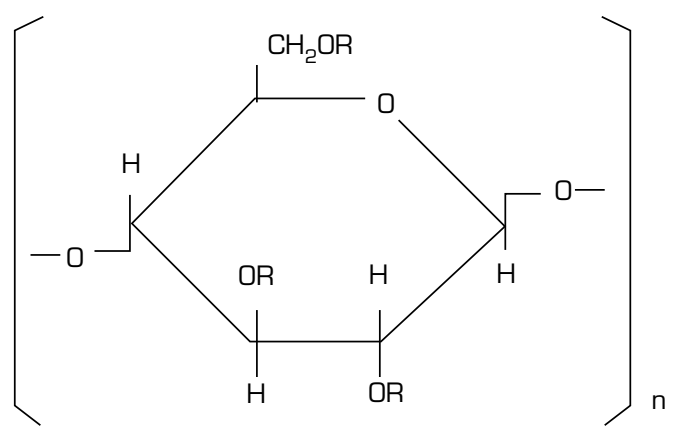

Figure 1. Monomer structure of methyl cellulose $(R=C H 3$ or $H)$ (Jyoti et al. 2014).

The structure of MC is largely identical to that of cellulose, with the exception of the -OR groups. In pure cellulose, these groups are hydroxyl groups with formula $-\mathrm{OH}$, but in $\mathrm{MC}$ some or all of these groups are replaced by methoxy groups with formula - $\mathrm{OCH}_{3}$ (Nasatto et al. 2015). The average number of replaced groups is indicated by the degree of substitution (DS). Ranging from zero to three, the DS determines whether the MC is of a hydrophobic or hydrophilic nature (Kobayashi et al. 1999).

When used as a gellant for ethanol, the MC must be hydrophobic as the gelling is primarily based on the hydrophobic effect. Due to the strong polarity of the ethanol and the weak or no polarity of the MC, the molecules do not mix and instead form a three-dimensional network of hydrophobic units held in place by weak inter and intra-molecular interactions. This, in turn, leads to a global increase in viscosity of the MC ethanol combination. Using higher concentrations of MC strengthens, the threedimensional structure further increases the viscosity of the gel. Both changes in temperature and applied shear rates can affect the integrity of the three-dimensional system, leading to further changes in gel viscosity (Jyoti et al. 2013a).

\section{Boron as an energetic additive}

Other than a gellant, energetic additives can also be added to the gel propellant to increase its energy content and density (Yang et al. 2020). A common additive is boron, which has the second highest heating value among all elements (Hashim et al. 2016) and is the most energetic metal additive (Haddad et al. 2011). Additional benefits are that, when using boron nanoparticles (e.g., $290 \mathrm{~nm}$ as used for this experiment), burn times are short and further energy is released through catalytic reactions (Fawls et al. 2003).

Although, overall, the inclusion of boron particles improves the fuel performance, it also leads to certain disadvantages that cannot be disregarded. First, the boron has a high activation energy and thus does not ignite as easily as the ethanol gel propellant it is combined with (Jyoti et al. 2017). Furthermore, boron oxide can form thin layers on fuel particles, hindering complete combustion (Grany 2014), and can lead to the clogging of the rocket nozzle (Pang et al. 2019).

The inclusion of boron nanoparticles as an additive is also in close relation to the propellant's nature as a gel. To be effective, the particles must be suspended throughout the fuel and may not precipitate from it, which is not readily possible for liquid propellants but can be done for gel propellants. In gel propellants, the high viscosity of the fluid prevents the settling of the metal particles, provided that the shear force exerted by the particles is sufficiently small (Beighley et al. 1970). Thus, the use of particles on the nanoscale aids in preventing sedimentation (Yang et al. 2020). Furthermore, it is advantageous to use amorphous boron, as was done in this experiment, rather than crystalline boron. The amorphous boron has a greater surface area (Fawls et al. 2003), which is believed to increase the attractive forces between nearby particles, further increasing the resistance to sedimentation (Yang et al. 2020).

\section{METHODOLOGY}

The preparation of the gels was conducted by Dr. B.V.S. Jyoti, co-author of this article. For the gelation of ethanol, it was made sure that the gelling agent used for the gelation process has been compatible and nonreactive with the parent fuel. The methyl cellulose (MC) was dispersed in the liquid ethanol by mixing the ingredients thoroughly for $30 \mathrm{mins}$ at $3000 \mathrm{rpm}$ with the help of a three-blade laboratory impeller. The suspension was stirred at room temperature $(298.15 \pm 1 \mathrm{~K})$ to ensure complete dissolution 
of the gellant in the fuel. In the case of metalized ethanol gel, after the thorough mixing of the MC, boron (B) metal particles were added with continuous stirring for complete dissolution of gellant and the incorporation of amorphous Boron metal particles in the fuel to achieve a homogenous mixture. The mixtures were then left undisturbed to allow a 3D network formation. In both the non-metalized and metalized case, stable ethanol gel fuels were prepared.

The gelation process is known to be affected not only by the type of gelling agent, but also by other parameters, such as processing temperature, mixing time, particle size of gellant and metal particle type.

The uniformity of the gelation process details was maintained during all the gelation experiments. Methyl cellulose in requisite concentrations of 8,9 , and $6 \mathrm{wt} \%$, were used for gelation of non-metalized and metalized ethanol. In the metalized ethanol gel case, critical gelling agent wt $\%$ was relatively less in comparison to non-metalized ethanol gel.

The measurement devices used to determine rheological properties are called viscometers. Common viscometers are the capillary viscometer, controlled stress rheometer and rotational viscometer (Chhabra and Richardson 2008). The later was used with a cone-and-plate geometry to obtain the data for this research. The cone-and-plate geometry viscometer is particularly good at measuring time-dependent behaviour of viscoelastic fluids. The test sample is placed in between a rotating cone and a static plate, so that a small angle is present between the two components. The exact geometry can be seen in Fig. 2. Through the rotation of the cone, the sample is subjected to the desired shear rate.

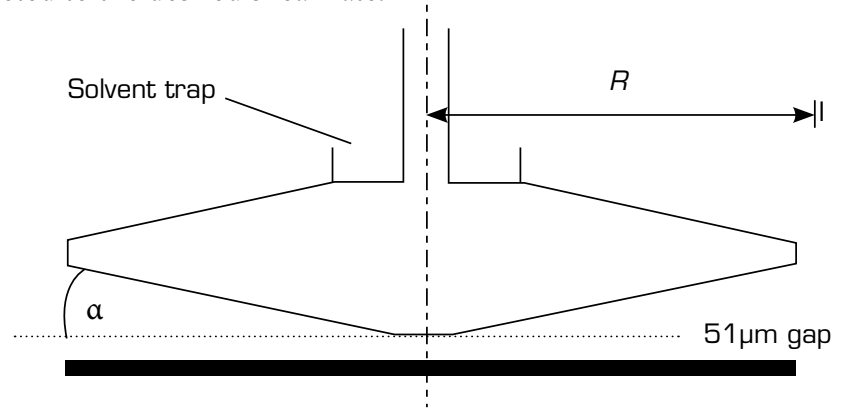

Figure 2. Cone-and-plate viscometer with angle $(a)$, radius $(R)$ and a $51.4 \mu \mathrm{m}$ gap between cone and plate (Chhabra and Richardson 2008).

The available data was obtained from several experiments. The data contains information about the relation between viscosity and both high and low shear rates, as well as the relation between viscosity and the different gelling agents used. The general method used for the data analysis was done by fitting mathematical models to the experimental data by applying the method of least squares regression, so that the behaviour of the investigated fluids can be predicted at any desired state. The data fitting was done by implementing numerical methods using computer programs.

For the research on chemical composition, no models were used. Instead, this part of the research is based on literature obtained from online research. This approach suffices in this case, since the section is not about data analysis but rather about presenting a discussion of the effects of gelling agents and additives on the rheology of the propellant. For the analysis of temperature and shear rate effects models were used. The relation between temperature and viscosity is described by an Arrhenius-type equation (Mahajan 2001). This equation is well suited for this research as it evinces the exponential behaviour of the investigated fluid and includes its activation energy, an important substance property. Furthermore, four models were used to investigate shear rate dependence (these models are: Power Law model, Cross Model, Carreau Model and Herschel-Bulkley Model. More information can be found by consulting the work of Jacobson [1991]). Each of these rheological models have their particular strengths and shortcomings, which are identified and compared, allowing a discussion about the best method to predict the gel propellant behaviour. By doing so, shear thinning and elastic behaviour can be investigated, which can yield very important information on the application of gel propellants in propulsion (Rahimi et al. 2007).

The aforementioned research on the relationships describing the viscosity of propellants is essential for the development of gel propellant rocket engines. For instance, it is important in the sizing of the propellant feeding system components, so that propellant accumulation and clogging at points in the feed system can be avoided (Rahimi et al. 2007). 


\section{RESULTS AND DISCUSSION}

The results and discussion section investigates in detail how the gel viscosity is affected by both temperature and the applied shear rate.

\section{Effects of temperature on gel viscosity}

Understanding the dependence of a gel rheology on temperature is critical when determining its operating temperature and limitations. Relationships such as the Arrhenius-type equation have proven successful in modelling the dependency of viscosity on temperature in certain temperature ranges. Data has been gathered on the gels apparent viscosities at different temperatures. In this section, the process of applying regression on the data to determine the unknown constants in an Arrhenius-type equation for each of the gels will be described. Furthermore, seeing that a sharp rise in viscosity beyond a distinct temperature is apparent, this will also be discussed.

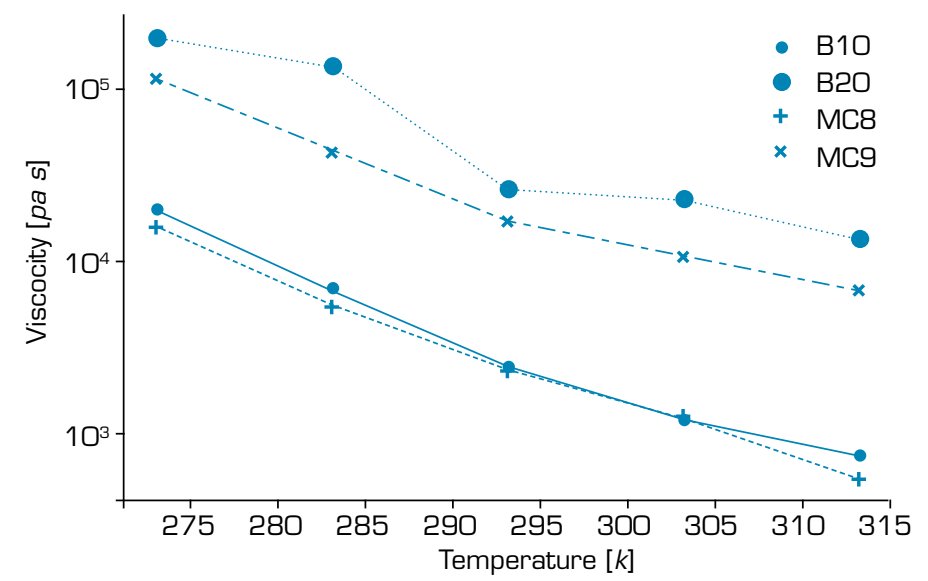

Figure 3. Logarithmic relation between temperature and viscosity for different gels.

\section{Data analysis}

Most fluids experience a decrease in viscosity with increasing temperature (Rahimi et al. 2010). This is because the additional thermal energy increases the translational energy of the molecules, allowing them to overcome the intermolecular attractive forces and weakening the semirigid structure of the fluid (Giap 2010). The gradient of this reduction is higher at lower temperatures and reduces in magnitude, or "flattens", as the temperatures rises. Thus, at low temperatures, the same absolute increase in temperature leads to a larger decrease in viscosity than at higher temperatures.

As seen in Fig. 3, this trend also holds for the studied ethanol gels. However, at higher temperatures, starting at 310 to $325 \mathrm{~K}$, a sharp rise in viscosity was observed. Here, the viscosity increases strongly and, in the case of the boron gels, it increases to even higher levels than the initial values measured at $273 \mathrm{~K}$. Although ethanol has a high latent heat of evaporation and its boiling point lies at $351 \mathrm{~K}$ (Kheiralla et al. 2011), it is believed that the sharp peaks in viscosity are linked to the evaporation of ethanol, brought on by the addition of heat to increase the gel temperature. If ethanol evaporates, the relative concentration of gellant in the mixture increases, which, as discussed in the section Materials, will lead to a higher viscosity. As seen by comparing the MC8 and MC9 curves in Fig. 3, a small increase in gellant concentration can significantly increase the gel viscosity.

The increase in viscosity is undesirable for applications of the ethanol gel propellant in rocket propulsion systems, where low viscosity is required, and thus places a temperature limit on the usability of the fuel. A solution would be to decrease the gellant fraction, such that even when the viscosity begins to increase, it remains low in absolute terms. 


\section{Modelling of measured data}

A very common choice of model to describe the relation between temperature $T$ (in Kelvin) and viscosity $\eta$ (in $\mathrm{Pa} \cdot \mathrm{s}$ ) is the Arrhenius-type equation stated in Eq. 1 (Rahimi et al. 2007). A central parameter in this equation is the activation energy $E_{\mathrm{a}}$ (in $\mathrm{J} \cdot \mathrm{mol}^{-1}$ ), which is analogous to the amount of energy required to disrupt the three-dimensional structure of the gel and thus reflects the strength of the fluid (Munialo et al. 2015). The model furthermore makes use of the gas constant $R$ (in $J K^{-1} \mathrm{~mol}^{-1}$ ) and the adjustable preexponential factor A.

$$
\eta=A \cdot e^{\frac{E a}{R \cdot T}}
$$

Table 1 shows the value of the activation energy for each gel, found by application of regression to fit Eq. 1. Regression was only applied to the range of the graph where viscosity showed an inverse relationship to temperature.

Table 1. Values for the activation energy required from the measured data

\begin{tabular}{ccc}
\hline & $\mathbf{E}_{\mathrm{a}}\left(\mathrm{kJ} \cdot \mathrm{mol}^{-1}\right)$ & $\mathbf{A}(-)$ \\
\hline MC8 & 56.29 & $2.62 \times 10^{-7}$ \\
\hline MC9 & 56.58 & $1.66 \times 10^{-6}$ \\
\hline B10 & 56.68 & $2.74 \times 10^{-7}$ \\
\hline B20 & 45.61 & $3.93 \times 10^{-4}$ \\
\hline
\end{tabular}

The theoretical trend can be compared to the measured data points to see how well the theoretical model fits the data. This can be seen in Fig. 4a for MC9 and Fig. 4b for B20. The plots only span the first six data points since the equation only applies to the region where the viscosity decreases with increasing temperature.

(a) Values for MC9

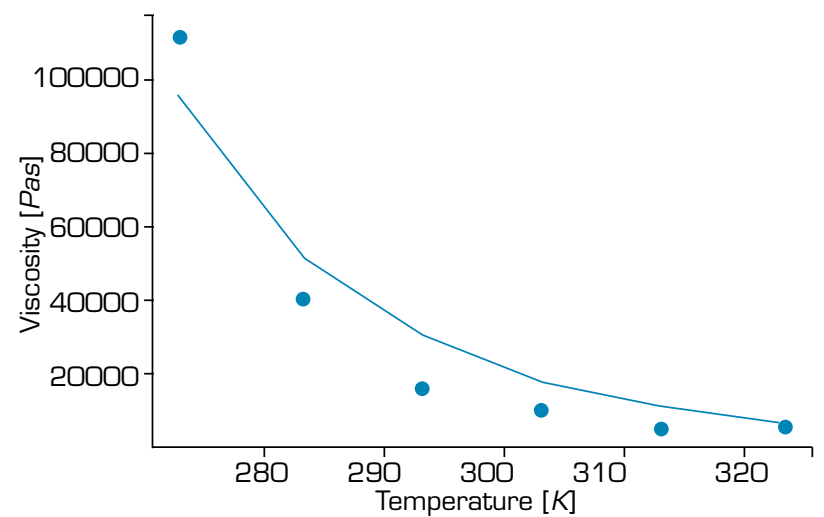

(b) Values for B2O

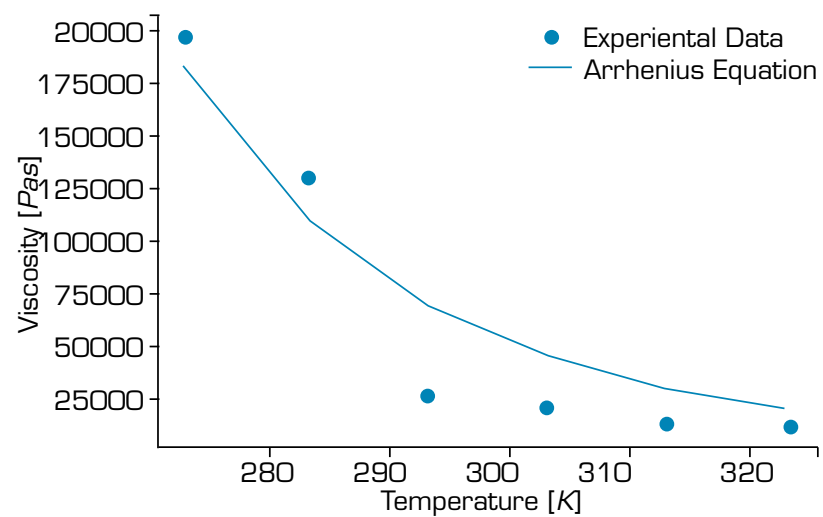

Figure 4. Theoretical and experimental values of viscosity versus temperature.

As can be seen in both graphs, the viscosity decreases faster with temperature than the Arrhenius equation suggests. As expected, due to the lack of experimental data, a perfect fit cannot be guaranteed, but the graphs show an adequate first order estimation of the relation between the viscosity and temperature of gel propellants.

\section{Effect of different additives}

The precise chemical composition of the gel can have significant impacts on the rheology of the propellant. As can be seen in Fig. 3, the curves corresponding to the different ethanol gel configurations differ by their vertical placement along the viscosity axis, but share rather similar slopes. This is reflected in the numerical values presented in Table 1: the values for the coefficient A 
differ greatly, partly by orders of magnitude, but the values for the activation energy, which determines the slope of the modelled curve, are more alike.

Nonetheless, there are differences between the activation energy values, which can be explained on the basis of the chemistry underlying the gel propellant. The B20 gel has an activation energy that is markedly lower than the values for the other gels. A likely explanation for this phenomenon is that the high percentage content of boron disrupts the bonding in the three-dimensional hydrophobic structure underlying the viscous nature. This weakens said structure, placing it in a transient state that is more susceptible to breaking down, decreasing the viscosity of the gel. Thus, less energy is required to activate the transition from the viscous to the less viscous state. Another apparent difference in activation energy is between the values for MC8 and MC9. As can be expected, the higher concentration of gellant in the MC9 gel appears to lead to a stronger three-dimensional structure that is more viscous and requires more energy to be broken down.

\section{Effects of shear rate on gel viscosity}

When shear is applied to a non-Newtonian gel, this has significant time-dependent effects on the viscosity of the fluid. The nature of these effects depends on whether the shear rate is high or low. Whereas high shear rates lead to shear thinning, at low shear rate an initial elastic shear thickening can be observed. This section discusses these two behaviours and how they can be modelled. The discussion is based on the shear rate dependent data collected for the pure ethanol-based MC8 gel (which does not contain any additive Boron).

\section{Behaviour at high shear rates}

Shear rates on the order of 10 to $1000 \mathrm{~s}^{-1}$ are common for systems involving pumps and the flow through pipes (Alderman 1997), making it desirable to accurately model the fluid behaviour in this regime. Multiple models predicting the gel behaviour shall be fitted to the experimental data and their performance shall be analysed.

The simplest of such models relating viscosity to the shear rate $\gamma$ (in $\left[s^{-1}\right]$ ) is commonly referred to as the power law. Stated in Eq. 2, the model relies on two constants that can be fit to the data at hand, the flow consistency index $K\left(\right.$ in $\left[P a s^{n}\right]$ ) and the dimensionless flow behaviour index $n$. Through variation of the exponent, the power law can model both shear-thinning and shear-thickening fluids, with a value of $n$ less than one corresponding to shear thinning (Nguyen Q-H and Nguyen N-D 2012).

$$
\eta=K \gamma^{n-1}
$$

The power law has the flaw that, for shear-thinning fluids, the predicted viscosity tends to zero as the shear rate goes to infinity. Experimental and theoretical insights, however, suggest the existence of a non-zero limiting value $\eta_{\infty}$ at infinite shear rate. A model that takes this into account is the Herschel-Bulkley model, stated in Eq. 3 in its shear rate dependent form (Giap and Amran 2011)

$$
\eta=K \gamma^{n-1}+\eta_{\infty}
$$

Another defect of the power law, which is shared by the Herschel-Bulkley model, is that the predicted values tend to infinity at low shear rates, whereas experimentation suggests that the viscosity remains finite. This led to the development of more elaborate models, including the widely used Cross and Carreau models. These models are stated in Eqs. 4 and 5 respectively and, using $\eta_{0}$ and $\eta_{\infty}$, both include limiting values for the viscosity at zero and infinite shear. They further make use of the relaxation time $a$ (in $s$ ) and the dimensionless power index $m$. (Barnes et al. 1989). Using a least-squares regression to evaluate the constant parameters for all of the models, yields the values listed in Table 2.

$$
\begin{gathered}
\eta=\eta_{\infty}+\frac{\eta_{0}-\eta_{\infty}}{1+(a \gamma)^{m}} \\
\eta=\eta_{\infty}+\frac{\eta_{0}-\eta_{\infty}}{\left(1+(a \gamma)^{2}\right)^{m / 2}}
\end{gathered}
$$


Table 2. Constants modelling ethanol gel propellant.

\begin{tabular}{ccc}
\hline Model & Parameter values & Least-squares error \\
\hline Power law & $K=13.44$ & 5.444 \\
$n=0.5598$ & \\
Herschel-Bulkley model & $K=13.40$ & 4.674 \\
& $n=0.6135$ & \\
$T_{\infty}=-0.3866$ & \\
\hline & $a=0.1012$ & 0.3022 \\
Cross model & $m=0.9903$ & \\
& $\eta_{\infty}=0.5765$ & \\
$\eta_{0}=12.31$ & 0.6491 \\
& $a=0.2048$ & \\
& $m=0.7071$ & \\
& $\eta_{\infty}=0.4146$ & \\
$\eta_{0}=11.10$ & \\
\hline
\end{tabular}

Clearly, the Cross and Carreau models give a significantly better regression of the data than the other two models, which suggests that it is important for the model to include a parameter that limits the viscosity to a finite value at zero shear rate. The differences can be seen in Fig. 5, which displays the different models alongside the original experimental data. The subplots are ordered according to ascending performance, starting with the worst-performing power law. The most accurate model to describe the relationship between viscosity and shear rate for this data set is the Cross model.
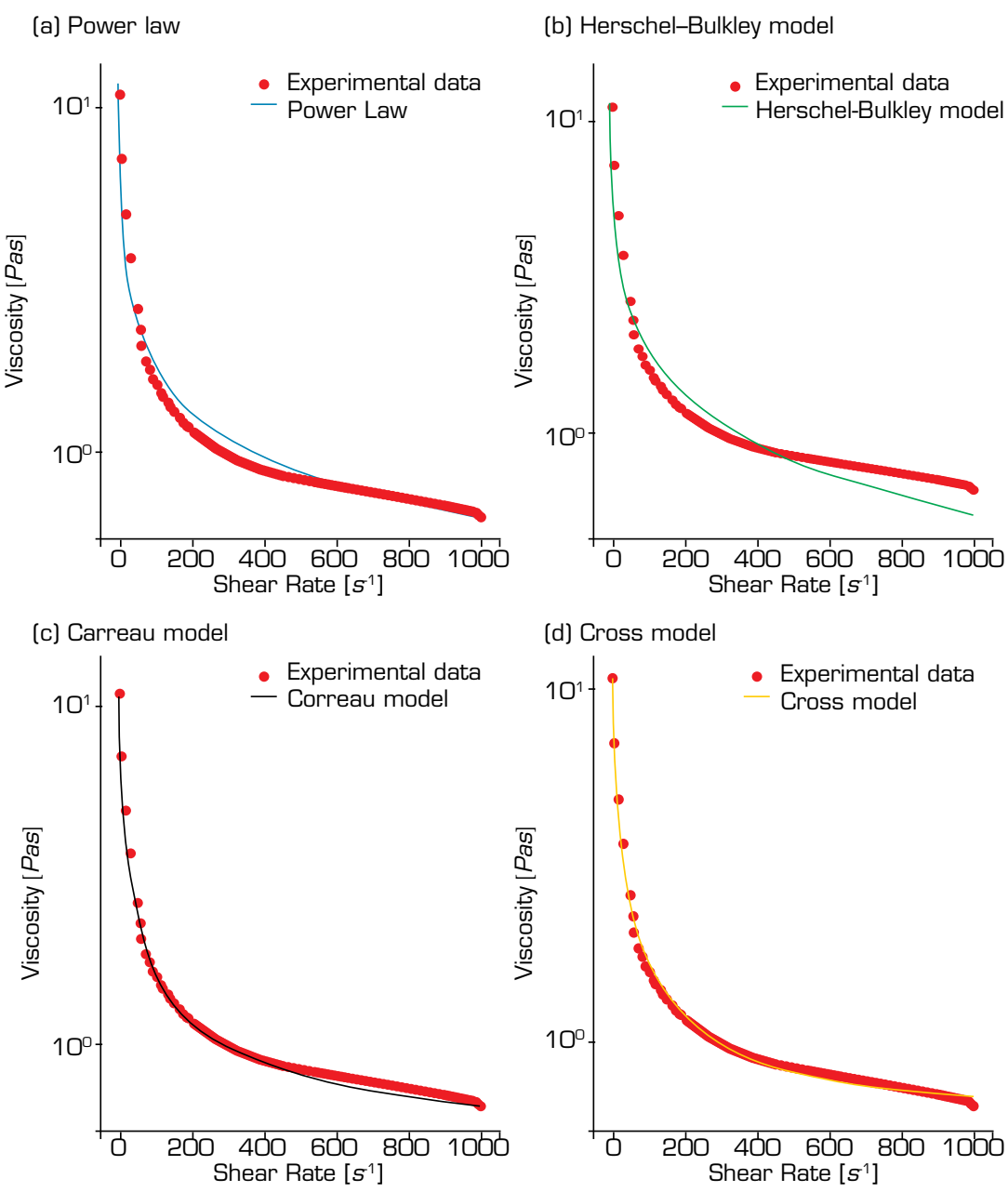

Figure 5. Viscosity versus shear rate for experimental data and the worst and best performing models. 
Another observation that can be made concerning the values in Table 2 is that the final value predicted by the HerschelBulkley model for the viscosity at infinite shear rate is an unrealistic value. The predicted value is negative and thus physically impossible. This highlights the limitations of this model and emphasizes that it should only be used to model the gel within the range of examined shear rates. The Carreau and Cross models, in contrast, offer more realistic values for the limit viscosity at increasing shear rates.

\section{Elastic behaviour}

For very low shear rates, the gel behaviour is of an elastic, shear thickening nature, and thus significantly different from what has been discussed previously. As shown in Fig. 6a, the viscosity initially increases linear-elastically with increasing shear rate, until it quickly reaches its maximum value. At this stage, the macroscopic structure of the gel breaks down (Malvern Instruments Limited 2015) and it starts to behave in a shear-thinning manner instead (Jyoti and Baek 2014). This linear behaviour is beyond the scope of the models discussed in the previous section, thus requiring a separate analysis.

The properties of the transition region are more clearly shown in Fig. $6 \mathrm{~b}$, which plots against shear stress rather than shear rate. The point of interest in this region is the yield point, which marks the elastic limit and is found to be at a viscosity, shear stress and shear rate of $68.89 \mathrm{~Pa} \cdot \mathrm{s}, 25.97 \mathrm{~Pa}$, and $0.41 \mathrm{~s}^{-1}$, respectively. Figure $6 \mathrm{~b}$ suggests that the experimental data may contain a number of outliers for shear stress, as multiple sources disagree with the general shape of the experimental graph (Jyoti et al. 2015; Jeon et al. 2010). Instead, a shape is suggested, such as that of the curve labelled "expected shape of data". This curve is an arbitrary adjustment of existing data points, created only to illustrate the expected shape, and is not fully supported by calculations. Based on the review of literature, the difference is presumed to be an experimental error, but it is a phenomenon to be aware of during further research and should be further investigated should it occur again.

(a) Viscosity versus shear rate

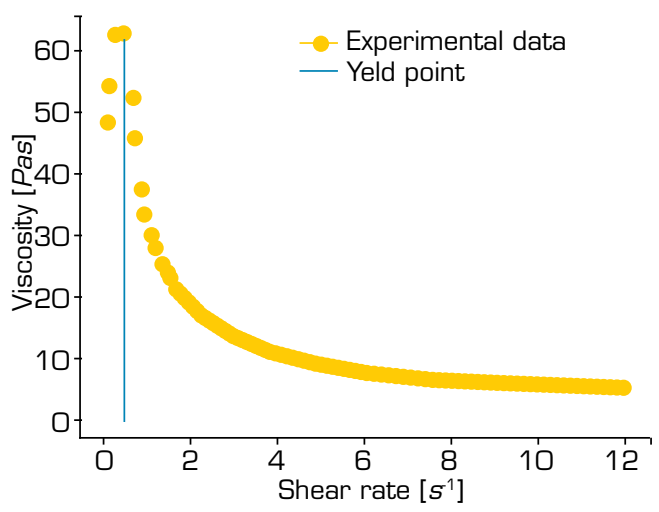

(b) Viscosity versus shear stress

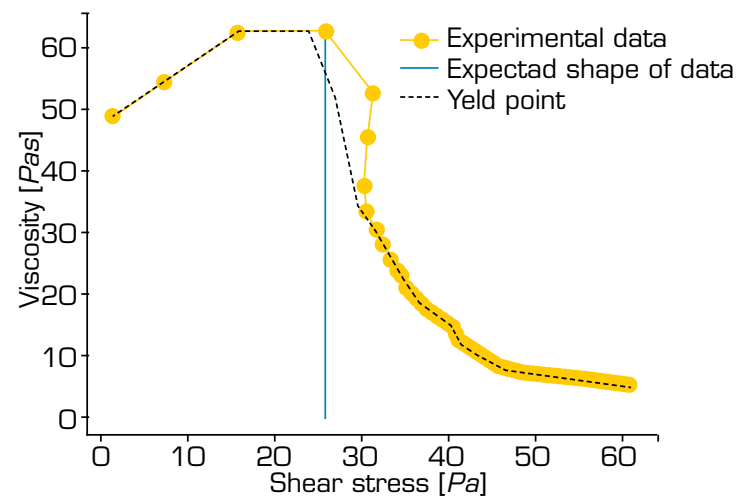

Figure 6. Elastic limit of the gel identified on different viscosity plots.

At the limit of elasticity, the relation between shear stress and shear rate changes as well, although in the shear thickening region, this relation is linear and thus elastic. Beyond the elastic limit of the gel, the relation becomes pseudoelastic (Björn et al. 2012) and nonlinear. This can be clearly seen from the experimental data shown in Fig. 7. The plot includes a curve labelled "expected shape of data", which reflects the curve shape suggested by literature on the basis of the rearranged Herschel-Bulkley model (Jyoti et al. 2015; Jeon et al. 2010). The nonlinear part of the graph can be modelled in the domain of viscosity versus shear rate using the methods already discussed in the previous section on high shear rates.

The initial shear thickening of the gel also has implications for its use as a propellant. A desirable consequence is that, to a certain extent, it aids in reducing fuel sloshing in propellant tanks. For small disturbances, the gel viscosity increases, thereby increasing the resistance against further fluid deformation. On the other hand, a high elastic limit means there is a high initial shear rate threshold that has to be overcome, which directly reflects on the feed-system design of gel rocket engines. 


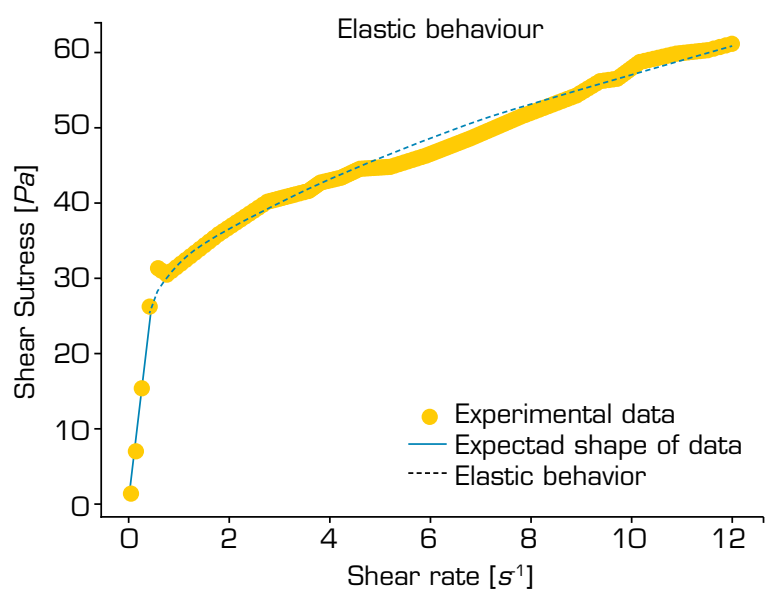

Figure 7. Elastic part of shear rate and shear stress graph of obtained data.

\section{CONCLUSION}

The research aim was to analyse the rheology of ethanol-based gel propellants for different temperatures and shear rates, while simultaneously varying the concentrations of MC gellant and boron additive, has been completed. By examining the shear rate and temperature data points for MC8, MC9, B10 and B20, the behaviour of the gels was modelled.

First, conclusions were drawn with respect to temperature. As temperature is increased, the gels viscosity decreases until approximately $320 \mathrm{~K}$, after which the viscosity starts to increase with temperature. Hence, the temperature should be limited to below the turning temperature of the gel. Furthermore, the activation energy of the gels was analysed. Most striking was that of the B20 gel, which was comparably low due to the effect of the boron nanoparticles on the three-dimensional gel structure.

At high shear rates, the gel shows a shear-thinning behaviour. Following an investigation of four commonly used models, it was identified that the Cross model provides the most accurate and realistic regression for predicting the flow behaviour of the MC8 ethanol-based gel propellant. The physically impossible value predicted by the Herschel-Bulkley model for the viscosity at infinite shear rate shows that the models should not be applied beyond the range of investigated values. Furthermore, at low shear rates, the gel behaves as shear thickening, an advantage for reducing fuel sloshing. It is concluded that up to a shear stress of $25.97 \mathrm{~Pa}$ and shear rate of $0.41 \mathrm{~s}^{-1}$, the gel behaves elastically, after which the gel behaves in a shear-thinning manner and viscosity decreases.

These results could provide the necessary building blocks to design gel propulsion systems in the future, since the design of these systems must be able to accommodate (and thus requires knowledge of) the unique rheological properties of the gels they aim to employ. Conclusions drawn with respect to the relationship between viscosity and temperature could prove to be useful in determining the operating temperature ranges that a gel propulsion system is required to facilitate. Likewise, modelling viscosity as a function of shear rate provides a better understanding of the gels as viscoelastic systems. Knowledge about the elastic behaviour gives insights into the required propellant storage conditions and knowledge about the viscous behaviour can provide the foundation needed to determine the required pressure to feed a gel propellant through feedlines.

To realize the usage of gel propellants as a viable option for propulsion, further research is needed. The use of more data points would strengthen the precision and reliability of the conducted analysis.

\section{AUTHORS' CONTRIBUTION}

Conceptualization: Jyoti BVS; Formal Analysis: Driever LX, Vinarskis A, Rhenman F, and Van de Sype O; Investigation: Jyoti BVS, Carer C, Driever LX, van der Toorn J, van Wezel C, Vinarskis A and Veiga CMA; Methodology: Jyoti BVS, Köbben 
S, Mckenzie M, Rhenman F, Van de Sype O, Vinarskis A and Driever LX; Project Administration: Jyoti BVS and Driever LX; Software: Driever LX, Vinarskis A, Rhenman F, and van der Toorn J; Supervision: Jyoti BVS; Validation: Jyoti BVS, Köbben S, Mckenzie M, Rhenman F, Van de Sype O, Vinarskis A and Driever LX; Visualization: Köbben S, Mckenzie M, Rhenman F and Sype O; Writing - Original Draft Preparation: Carer C, Driever LX, van der Toorn J, van Wezel C, Köbben S, Mckenzie M, Rhenman F, Van de Sype O, Vinarskis A and Veiga CMA; Writing - Review \& Editing: Jyoti BVS, Carer C, Driever LX and van der Toorn J.

\section{DATA AVAILABILITY STATEMENT}

All data sets were generated or analysed in the current study.

\section{FUNDING}

Not applicable.

\section{ACKNOWLEDGEMENTS}

Not applicable.

\section{REFERENCES}

Aggarwal R, Patel IK, Sharma PB, Thirumalvalavan K (2015) A comprehensive study on gelled propellants. International Journal of Research in Engineering and Technology 4(9):286-290. https://doi.org/10.15623/ijret.2015.0409053

Alderman NJ (1997) Non-Newtonian fluids: guide to classification and characteristics. London: ESDU.

Barnes HA, Hutton JF, Walters K (1989) An introduction to rheology. Amsterdam: Elsevier.

Beighley CM, Fish WR, Anderson RE (1970) Advanced fuels and oxidizers. In: Partel GA, editor. Space Engineering: Proceedings of the Second International Conference on Space Engineering. p. 163-189. https://doi.org/10.1007/97894-011-7551-7_13

Björn A., Monja PS, Karlsson A, Ejlertsson J, Svensson BH (2012) Rheological characterization. London: IntechOpen. p. 6376. https://doi.org/10.5772/32596

Chhabra RP, Richardson JF (2008) Non-Newtonian flow and applied rheology: engineering applications. Oxford: Butterworth-Heinemann.

Ciezki HK, Naumann KW, Weiser V (2010) Status of gel propulsion in the year 2010 with a special view on the German activities. Deutscher Luft-und Raumfahrtkongress 2010.

Ciezki HC, Kirchberger C, Stiefel A, Kröger P, Pinto PC, Ramsel J, Naumann KW, Hürttlen J, et al. (2017) Overview on the German gel propulsion technology activities: status 2017 and outlook. Paper presented 7th European Conference for Aeronautics and Space Sciences EUCASS; Munich, Germany. https://doi.rog/10.13009/EUCASS2017-253 
Fawls CJ, Fields JP, Dunn TJ, Elstrodt D, Hudson ML, Wagaman KL, Kuo K (2003) Propellant composition comprising nanosized boron particles. US Secretary of Navy US 6625682B1.

Giap SGE, Amran A (2011) Dynamic viscosity as a function of shear rate: The comparison of established rheological models with the newly derived rheological model for the estimation of zero - and infinite - shear rate viscosity of vegetable oils. J Teknol 54(Jan. 2011):111-120. https://doi.org/10.11113/jt.v54.95

Giap SGE (2010) The hidden property of Arrhenius-type relationship: viscosity as a function of temperature. J Phys Sci 21:29-39.

Grany A (2014) Thermodynamic limitation on boron energy realization in ramjet propulsion. Acta Astronaut 98:128-132. https://doi.org/10.1016/j.actaastro.2014.01.023

Haddad A, Natan B, Arieli R (2011) The performance of a boron-loaded gel-fuel ramjet. Progress in Propulsion Physics 2:499-518. https://doi.org/10.1051/eucass/201102499

Hashim SA, Lahariya M, Karmakar S, Roy A (2016) Calculation of theoretical performance of boron-based composite solid propellant for the future applications. In: Bajpai RP, Chandrasekhar U, editors. Innovative Design and Development Practices in Aerospace and Automotive Engineering. Singapore: Springer. p. 327-335. https://doi.org/10.1007/978-981-10-1771-1_35

Jacobson BO (1991) Rheology and elastohydrodynamic lubrication. Amsterdam: Elsevier.

Jeon K-H, Ryu D-W, Kim H-M, Park E-S, Song J-J (2010) Numerical analysis of grout flow and injection pressure affected by joint roughness and aperture. J Korean Soc Rock Mechan 20(2):82-91.

Jyoti BVS, Varma M, Baek SW (2013a) Comparative study of rheological properties of ethanol and UDMH based gel propellants. Paper presented 5th European Conference for Aeronautics and Space Sciences. EUCASS; Munich, Germany.

Jyoti BVS, Baek SW, Lee DG, Lee JH (2013b) Formulation and comparative study of rheological properties of metallized and non-metallized ethanol-based gel propellants. Paper presented Asia-Pacific International Symposium on Aerospace Technology. APISAT; Chengdu, China.

Jyoti BVS, Lee DG, Baek SW, Lee JW (2013c) Formulation and characterization of eco-friendly ethanol gel propellant. Paper presented 21th International Symposium on Air Breathing Engines. ISABE; Munich, Germany.

Jyoti BVS, Baek SW, Lee DG (2014) Rheological characteristics of ethanol-based gel propellant. Paper presented 2014 International Conference on Advanced Materials, Testing and Information Engineering. AMTIE; Shenzhen, China. https:// doi.org/10.5139/IJASS.2014.15.2.199

Jyoti BVS, Baek SW (2014) Rheological Characterization of Metalized and Non-Metalized Ethanol Gel Propellants. Propellants Explos Pyrotech 39(6):866-873. https://doi.org/10.1002/prep.201400085

Jyoti BVS, Baek SW (2015) Formulation and Comparative Study of Rheological Properties of Loaded and Unloaded EthanolBased Gel Propellants. J Energ Mater 33(2):125-139, https://doi.org/10.1080/07370652.2014.939311

Jyoti BVS, Naseem MS, Baek SW (2017) Hypergolicity and ignition delay study of pure and energized ethanol gel fuel with hydrogen peroxide. Combust Flame 176:318-325. https://doi.org/10.1016/j.combustflame.2016.11.018

Kheiralla AF, El-Awad M, Hassan MY, Hussen MA, Osman HI (2011) Effect of Ethanol-Gasoline Blends on Fuel Properties Characteristics of Spark Ignition Engines. UofKEJ 1(2):22-28.

Kobayashi K, Huang C, Lodge TP (1999) Thermoreversible Gelation of Aqueous Methylcellulose Solutions. Macromolecules 32(2)1:7070-7077. https://doi.org/10.1021/ma990242n

Mahajan S (2001) Encyclopedia of Materials: Science and Technology. Oxford: Pergamon Press. 
Malvern Instruments Limited (2015) Understanding Yield Stress Measurements. Worcestershire: Malvern. [accessed Jun 16 2020]. https://cdn.technologynetworks.com/TN/Resources/PDF/WP120416UnderstandYieldStressMeas.pdf

Munialo CD, van der Linden E, Jongh, HHJ (2015) Activation energy of the disruption of gel networks in relation to elastically stored energy in fine-stranded ovalbumin gels. Food Hydrocoll 55:163-171. https://doi.org/10.1016/j.foodhyd.2015.11.014

Nasatto PL, Pignon F, Silveira JLM, Duarte MER, Noseda MD, Rinaudo M (2015) Methylcellulose, a Cellulose Derivative with Original Physical Properties and Extended Applications. Polymers 7(5):777-803. https://doi.org/10.3390/polym7050777

Natan B, Rahimi S (2001) The status of gel propellants in year 2000. Int J Energetic Mater Chem Propul 5(1-6):172-194. https://doi.org/10.1615/IntJEnergeticMaterialsChemProp.v5.i1-6.200

Nguyen Q-H, Nguyen N-D (2012) Incompressible Non-Newtonian Fluid Flows. In: Gan YX, editor. Continuum Mechanics - Progress in Fundamentals and Engineering Applications. London: IntechOpen. p. 47-72. https://doi.org/10.5772/26091

Pang WQ, Luca LT, Fan XZ, Glotov OG, Zhao FQ (2019) Boron-Based Fuel-Rich Propellant: Properties, Combustion, and Technology Aspects. Boca Raton: CRC Press. https://doi.org/10.1201/9780429030680

Rahimi S, Peretz A, Natan B (2007) On Shear Rheology of Gel Propellants. Propellants Explos Pyrotech 32(2):165-174. https://doi.org/10.1002/prep.200700018

Rahimi S, Peretz A, Natan B (2010) Rheological Matching of Gel Propellants. J Propuls Power 26(2):376-379. https://doi. org/10.2514/1.42904

Ryan-Mosley T, Winick E, Kakaes K (2019) The number of satellites orbiting Earth could quintuple in the next decade. MIT Technology Review [Internet]. [accessed Apr 29 2020]. https://www.technologyreview.com/2019/06/26/755/satelliteconstellations-orbiting-earth-quintuple/

Ryan-Mosely T, Winick E, Kakaes K (2020) Global Space Industry Dynamics: Research Paper for Australian Government, Department of Industry, Innovation and Science by Bryce Space and Technology, LLC. Alexandria: Bryce. [accessed May 2 2020]. https://www.industry.gov.au/sites/default/files/2019-03/global_space_industry_dynamics_-_research_paper.pdf

Yang D, Xia Z, Huang L, Ma L, Chen B, Feng Y (2020) Synthesis of metallized kerosene gel and its characterization for propulsion applications. Fuel 262:116684. https://doi.org/10.1016/j.fuel.2019.116684 